\title{
Boulding's Lamentation And The Equilibrium Model Of Luca Pacioli: An Examination Of Cross-Disciplinary Misunderstandings
}

\author{
James H. Baskett (E-Mail: jjbaskett@earthlink.net) Loyola University of New Orleans
}

\begin{abstract}
This treatise addresses an interdisciplinary issue addressed by Kenneth Boulding, who lamented the difference in usage of Pacioli' accounting model as between economic theorists and accountants. In response, this treatise examines origins of the accounting model, and the evolution of its use are traced. Differences between economists and accountants are examined through the filter of Luca Pacioli' bookkeeping model, the flawed foundation upon which all generalizations regarding accountancy have been based for centuries. The economic nature of financial accounting models is detailed and similarities and differences between theoretical and applied models of financial accounting are examined. Pacioli' applied model is re-examined in economic terms befitting its primal nature. The economic meaning underpinning bookkeeping terms is clarified, and the breach between accounting practice and literature and the solid economic reality underlying the accounting process is discussed The mutual misunderstanding which gave rise to Boulding' dilemma is placed in its primal context, and requirements for its resolution are suggested.
\end{abstract}

\section{Introduction}

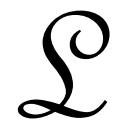

uca Pacioli was a mathematician who, for reasons that have remained somewhat obscure, took an interest in business and the accounting process and, due to his original contribution to the literature of accountancy, has been called the father of accounting. It is reasonably certain that business owners and/or creditors understood the requirements of the accounting model for which Pacioli has become known and revered before he committed it to writing in 1494 A. D. In fact, there are indications that the bookkeeping methods which Pacioli detailed in his Summa de Arithmetica, Geometria, e Proportioni et Proportionalita (Hereafter cited as Summa) treatise was taken in part from the writings of Leonardo di Pisa, who wrote an important book in the year 1200 A. D. There is very strong reason to believe that Arabs who introduced their system of algebraic notation to the Italians also introduced the concept of double entry bookkeeping even before di Pisa's time. (Richard H. Macve, page 11) The true originator of double-entry bookkeeping is also lost in history, but merchants in Europe and the Arab world had gravitated to its use before Pacioli's era. A wealthy Tuscan merchant banker is know to have used double entries in his records more than a hundred years before Pacioli's treatise was published, and it has been said that the basic structure of the method Pacioli described was used by merchants two hundred years before Pacioli. (Macve, pages 11-12) Whatever the chronology, it is clear that merchants in Venice were using the method at the time Pacioli committed it to writing. (Emmett R. Miller, pages 60-76) The fact that merchants used and understood the model before it was committed to writing is an important clue to the meaning and origin of Pacioli's model. Pacioli himself focused on the bookkeeping requirements of applied accountancy rather than the underlying nature of accountancy due to his focus on existing uses of applied

Readers with comments or questions are encouraged to contact the author via email. bookkeeping techniques by merchants of his era.

In committing to writing what was likely a commonplace practice among Venetian merchants, his focus 
was on the precise manner in which accounting entries were required to be made, a tendency which, while forming the basis for what accountants the world over practice to the present day, also entailed unwanted consequences which continue to haunt the accounting profession; it also perpetuates a chasm of misunderstanding between economists and accountants. His terms "debito" and "credito," which indicate "leftness" and "rightness" according to some authors, and which are still used today, do not reflect the reality of the accounting model which Pacioli recorded, and have caused most in the accounting profession to focus on what was a particular choice for bookkeeping methods for his treatise rather than on the underlying nature of accountancy itself.

Economists have a continuing interest in financial accounting realities because they correctly understand financial accounting to be the practice of applied economics. However, economists traditionally tend to deprecate some of the efforts of practicing financial accountants, as indicated in the following statement: "Economic theorists . . must remember that the rules of thumb, approximations and customary activities of the business community are not merely irrelevant ephemera to the business community and not merely irrelevant ephemera to the theorist ...." (Martin Shubik, page 234) The attitude manifested here has resulted in part because, as regards many aspects of financial accounting for economic entities, accounting practitioners and economic theorists have remained separated by an intellectual chasm. Kenneth Boulding, a famous economic theoretician has pensively remarked:

Economics and accountancy draw their raw material from much the same mines. However, they seem to fashion remarkably different products. They both study the operation of firms; they both are concerned with such concepts as income, expenditure, profits, capital, value and prices. In spite of an apparently common subject-matter, however, they often seem to inhabit totally different worlds, between which there is remarkably little communication. (Kenneth Boulding, page 44)

Practitioners in the accounting profession have been unable to address this lament by Boulding because of widespread (almost universal) misunderstanding within the accounting profession of the economic meaning of Pacioli' model. Economists themselves have no answer for the questions Boulding raises because of their failure to appreciate the manner in which the natural limitations of the applied bookkeeping process differ from the economic reality which they attempt to model in their theoretical constructions of the underlying accounting process. The accounting literature is replete with accountants who mischaracterize the nature of accounting because they fail to appreciate the underlying theoretical nature of accounting; economists are equally prolific in misstating the nature of applied accountancy, due to their failure to appreciate the underlying accounting model and its connection to applied accountancy. Some published statements reflecting such misunderstanding will be examined below in this treatise.

While certain of the differences between these disciplines have been reduced in recent decades as financial accounting practices have evolved toward inclusion of more economic reality, a significant chasm persists, one which can be remedied only when there is a mutual understanding of the primal accounting process by both groups of professionals. This treatise will examine Boulding's dilemma from the perspective of both practical accountants and theoreticians within the accounting and economic professions, in order to promote a common bridge of understanding between the two communities. To that end, this treatise will redefine what accountants are doing as they practice their craft, and introduce new terminology which is needed to be more consistent with economic realities underlying the applied accounting process.

\section{The Economic Foundation of Accounting Models}

There is a common foundation upon which all models of accounting are built: The recorded aggregate value of assets controlled by an accounting entity are required, at every instant in the life of the entity, to be equal to the recorded aggregate value of the legal claims against those assets. (F. W. Cronhelm, page 1). This is nothing more than a reflection of the economic reality attending all accounting entities. This equilibrium requirement is the sine qua non of all financial accounting models worldwide, and at all times in history: It cannot be violated for any reason. This requirement makes it apparent that any model of applied accountancy is, by primal nature, a dynamic economic equilibrium model of an accounting entity. The manner in which financial accountants adhere to this equilibrium requirement is through use of original bookkeeping entries representing descriptions of economic events affecting such entities. Such descriptions of economic events form a direct, although imperfect, link between the financial accounting process and the economic reality, which that process describes. 
The financial accounting process used in all eras by accountants worldwide purports to recognize all economic events affecting an accounting entity in a manner consistent with the equilibrium requirement. The financial accounting process commences with identification of economic events relevant to an accounting entity, proceeds by recording and processing such events in a systematic way, then concludes by communicating a periodic summary of economic events to interested users through the medium of financial statements. The particular period chosen for periodic reporting could conceptually end after each economic event is recorded, but accountants choose longer periods for convenience and cost effectiveness. Recorded economic events represent, in the aggregate, all financial information entering the accounting information stream, and, at every moment in the life of an accounting entity, a summary description of all economic events which have affected it during its existence, up to a specific point in time. This "economic-event" linkage between economic reality and accounting models is the primary common ground upon which theorists and practitioners in the accounting arena tread.

Accounting entities may be legal entities, such as corporations, or other than legal entities, such as sole proprietorships or partnerships. They may also be the whole of or sub-parts of the above. Each such entity must satisfy three criteria: It must be an economic entity; economic events affecting the entity must be specifically identifiable and measurable; and financial accounting records must be kept to document economic events affecting the entity. Accounting entities can be privately or publicly owned, and might be profit or not-for-profit entities. It will be assumed below, for simplicity of exposition, that accounting entities referenced are privately owned, profit-seeking organizations.

\section{Economic Events in the Financial Accounting Model}

An economic event is any occurrence affecting either the aggregate amount or composition of economic resources controlled by an accounting entity (Edgar O. Edwards et al., page 5). The term "economic resources" refers to the recorded value, measured in money, of assets controlled by an entity, but may also be seen as the value in money of legal claims owners and creditors have against those same assets, as these aggregates must remain measurably equal at every moment in the life of an accounting entity. Stated differently, the recognition of the existence of assets controlled by an accounting entity always implies legal claims equal to the value of those assets and viceversa. Non-economic events (those occurrences that do not directly affect entity resources and cannot be measured in money) are not necessary to the accounting model, but, if they are entered in accounting records, they are intended to provide informational data, not economic resources data.

An economic event might arise from an objective exchange transaction, but might be implicit, as when certain asset(s) increase or decrease in value while held by an entity. When economic events are supported by objective evidence, they can be precisely measured or reasonably estimated in terms of money; these events can be recorded generally with more precision than implicit events, which may occur without benefit of an immediately observable transaction. Evidence supporting implicit events is normally indirect and difficult to verify independently or estimate with reasonable assurance. Despite this limitation, for an accounting model to be theoretically complete, all economic events, whether explicit or implicit, should be invariably recorded in order to achieve a complete presentation of requisite financial facts. That they are not so recorded in practice is a salient difference between applied accountancy and theoretical descriptions of the financial accounting process.

Economic events may impact entity resources in two principal ways. First, the aggregate value of resources controlled might be affected by an event, as when owners or creditors directly alter their capital committed to an entity, when earnings transactions take place, or when gains or losses are realized, so that the asset base and the legal claims against the entity are changed. Second, composition of resources might be affected without any immediate effect on the aggregate value of resources controlled, as when one asset is exchanged for another of equal value; also, the composition of legal claims only may be affected, as when one liability is exchanged for another, liabilities are liquidated by issuance of ownership interest, or preferred stock is converted into common stock, all without realized gain or loss. That the implications of this fact for bookkeeping has not been widely understood explains much of the veil of confusion which has obscured the link that goes from bookkeeping to primal accountancy.

\section{The Duality of Economic Events}


Dual entry accounting arises from, and becomes possible only because of, the following universal fact pertaining to accounting entities: At every moment in the life of an accounting entity, the aggregate value of economic resources controlled must be shown to be equal to the value of aggregate legal claims against those resources by outside agents (owners and creditors), and the particular assets and particular legal claims must be clearly identified at all times. This means that there is an inherent economic duality in the primal model of accounting.

Every economic event is a composite of separable activities, a "sourcing event" and a "using event." The economic resource value of each economic event must be measured as the value in money of its related resource sourcing activity, or as the value in money of its related resource using activity, as these activities must be measurably equal and offsetting. The process of financial accounting allows no exceptions.

Since a simultaneous reckoning of sourcing and using activities is required within each and every economic event, dual-entry recordation has become the logical and inevitable format of choice for applied financial accounting models. Every entry into the financial accounting information stream relating to economic events must recognize, preserve the equality of, and indicate the offsetting nature of, sources and uses of entity resources, according to dictates of the economic equilibrium model it proxies. The particular format of accounting entries can vary. Pacioli's method and the terminology he used to describe entries represents just one among many possible choices. All such choices of bookkeeping, however, must be consistent with the primal economic nature of accountancy.

\section{The Nature of Sourcing Activities}

A sourcing activity is a necessary sub-part of every economic event because each economic event requires fuel (in the form of economic resources), and sourcing activities provide that fuel. Sources of fuel for a particular transaction may be internal (existing resources are used to fuel the event) but might also be external (resources are augmented from outside the entity).

Provision of resources is external when owners, creditors or donors infuse new resources, resulting directly in increased aggregate creditor or ownership legal claim(s) against the aggregate of increased entity assets, combined with a corresponding increase in assets controlled or with a decrease in other legal claims against existing assets. All such increases in particular legal claims invariably represent a source of entity resources. It is important to recognize that particular sourcing events do not necessarily imply an increase in aggregate legal claims. For example, they can represent a change in the composition of those claims only, as when one creditor or ownership claim is increased (a sourcing activity) through exchange for (diminution of) another such legal claim (a using activity); sourcing activities can also occur with no change at all in such claims (as when existing assets are used as fuel for an event).

An increase in the value of any asset(s) controlled always manifests an internal source of entity resources. When, for example, cash is used as a resource to pay existing liabilities, or if a cash dividend is paid, the cash asset disposed of represents internal resources used to fuel a transaction. Similarly, if a non-cash asset is acquired with cash, or if an existing non-cash asset is used to barter for other assets, the asset(s) given up provide(s), or sources, the economic resources that fuel an economic event.

Activities resulting in realization of operating revenues or non-operating revenues or gains always represent a source of entity resources, as do gifts received and windfalls to which an entity is beneficiary. All of the above result, other things equal, in an increase in owner's legal claims against entity assets, as has been indicated above.

\section{Using Activities and Entity Resources}

Using activity is a second necessary type of activity associated with every economic event. Every recorded using activity represents recognition of a disposition of entity resources that have been provided by a contemporaneous sourcing activity. Such use or disposition of resources might be internal with respect to an accounting entity, but can also be external. 
Uses of entity resources are internal when any economic event results in an increase in the value of any asset controlled by an entity. Note that this does not imply an increase in aggregate assets held, because, in particular cases, certain asset(s) might increase and other(s) decrease in equal value as a result of an economic event; the value of any asset(s) increased invariably entails a disposition of resources, however, just as a decrease in value of another asset represents a source of resources as fuel.

By contrast, when an economic event results in a reduction in the value of any legal claims of owners or creditors against entity assets, such diminution always reflects a disposition of entity resources, just as an increase in the value of asset(s) will do. The diminution of existing legal claims might be accomplished by using existing assets to pay creditors or liquidate ownership interests, in which case a reduction in aggregate size of an entity is implied, but might also result from creation of new and differing legal claims as replacements. Stated differently, the choice to use existing resources to reduce any of the legal claims against entity assets requires an external disposition of resources, which invariably is a using activity. If creation of new legal claims occurs in tandem with a decrease of other legal claims, the disposition is external, but doesn't necessarily decrease the size of the entity, other things equal (The author understands that any such transaction should properly be disaggregated into two transactions, but ignores that here only in order to make the ultimate point regarding entity size).

Economic activity resulting in the incurrence of either operating or non-operating expenses, realization of operating or non-operating losses, payment of dividends, or gifts made always represent a use of entity resources. Note that each of these ultimately implies a reduction in ownership claims against entity assets, since they result in the diminution of retained earnings, other things equal.

\section{Alternative Models of Financial Accounting}

Two broad approaches to modeling the financial accounting process are possible, one of which is theoretical, the other applied (or practical). Economists are predisposed to use the theoretical (or primal) variant, while practical accountants are able to follow the theoretical model only up to the degree mandated by practical realities. Viewed from the perspective of existing applied accounting systems worldwide, there are numerous gradations within these extremes, because certain compromises to what is theoretically possible are always made in implementing a financial accounting model. The choices made within a particular country as to the mix of theoretical and practical aspects utilized in their applied accountancy are determined by cultural influences, types of economies involved, and historical accident, among other factors. Nevertheless, it will be assumed, solely for purposes of exposition, that only the two extremes--the theoretical, primal variant and one practical variant--exist.

Whether theoretical or applied, the financial accounting process is required to be implemented within a dynamic equilibrium model. Equilibrium in the modeling context requires aggregate net uses of entity resources and aggregate net sources of entity resources to be measurably equal in value before and after every recorded economic event in the life of an accounting entity. (Cronhelm, pages 1-7) All financial accounting models are required to be "dynamic" because every economic event must disturb an existing equilibrium by affecting either the existing aggregate value of, or composition of, entity resources, then simultaneously restore a new equilibrium. This occurs because the aggregate value of related sourcing/using activities must remain equal before and after every economic event, without exception. Within either approach, aggregate uses are measured as the recorded value in money of entity assets, and aggregate sources are measured as the recorded value in money of the legal claims against entity assets, at a specific point in time.

Theoretical economists (including theoreticians within the financial accounting community) and practical financial accountants have generally viewed the financial process from differing perspectives. Theoreticians tend to approach the process from a perspective of "What is conceptually possible when utilizing the primal variant of the dynamic equilibrium model?" whereas practical financial accountants have been bound by the strictures of utilitarian, applied economics (i.e., "What is practicable, given the practical realities of the accounting entity being modeled?"). An incomplete attempt to synthesize the two approaches has been made by Boulding (pages 44-55). Since all theoretical economists and practical accountants are confronted with the same set of financial facts affecting each accounting entity, but frequently reach different conclusions from their respective analyses at a point in time, it might be said that each group is utilizing a different "accounting model." 
The "practical financial accounting model" employed by accountants is well known, since accounting principles have been systematically promulgated, but a "theoretical economic accounting model" has not been analogously reduced to a set of principles and conventions. The theoretical variant is best thought of as the sum of observations which economists and other theoreticians typically make regarding the accounting process; it becomes most visible when economists take exception to work done by practical accountants, although. However they might approach it, economists are trying to adhere to what is primal with respect to economic realities that underlie all of accountancy. Thus, while there is no promulgated theoretical accounting system per se, a model can be inferred from what theoreticians say; this will be termed the "theoretical" or "primal model" to differentiate it from the "practical" or "applied" model which accountants must employ. While the theoretical model and applied financial accounting models are far from mutually exclusive, salient differences remain, perpetuating confusion between both professional groups. Some of these differences will be examined below.

\section{A Theoretical Model of Financial Accounting}

A theoretical model, in purest primal form, would include an assumption of perfect knowledge of economics events affecting an accounting entity. All economic events, objective and implicit, would be assumed to be identified simultaneously with their occurrence, measurable exactly and completely in money, and then recorded immediately without error.

An assumption of perfect knowledge of economic events would have numerous implications for financial accounting modeling, some of which are obvious. First, since assets controlled by an entity and legal claims against those assets are required, by assumption, to be correctly valued at all times, there could be no differences among recorded value, fair market value, and liquidation value of resources controlled. This implies that entity income or gains and losses from every source would be assumed immediately known and accurately recorded. In addition, all recorded estimates would be assumed precise (The recorded amount of depreciation expense would, for example measure exactly the periodic decrement to value of entity resources from capital consumption, as would be confirmed if an asset were sold for fair market value). Second, there would be no difference between gains and losses recognized and realized. Third, there would be no uncertainties, in the sense that the outcome of all potentially contingent situations would be known immediately. Moreover, all economic resources would be assumed susceptible to being accurately valued in a single monetary unit of current purchasing power. These are assumptions that economists generally make in their thinking about the financial accounting process.

A theoretical model differs from an applied model because practical accountants cannot identify every economic event immediately, might not record every event identified due to an absence of objective confirmation, and they are faced with many measurement alternatives surrounding economic events, none of which might meet the test of theoretical correctness. Even when the existence of an economic event is identifiable, and objective evidence supports recordation, accountants often are lead by prudence to choose, as a conservative practice, not to record the event, as often occurs when assets are known or suspected (by appraisal?) to be valued above historical cost, yet appreciation is not recorded. This conservative practice could also be called the "practice of lesser evil," since not recording an event at all might not be as bad as recording a misleading value representing that event.

Since recorded economic events form the basis for valuing assets and measuring periodic income, the twomodeled approaches would logically be expected to reach different conclusions regarding financial aggregates. Income that would be measured within a theoretical model is often termed "economic income" to distinguish it from "accounting income," which can be a less inclusive measure. An economic income measure would compare entity wealth at the end of a period to wealth at the beginning of the period, but accretions and decretions to wealth would be from both explicit and implicit events, past and future, whereas accountants cannot realistically include the precise earnings impact of certain implicit events. Employing a theoretical approach does not, per se, solve the problem of defining economic income for an accounting entity even for theoretical economists, as indicated below:

Economists cannot agree upon a single concept of income .... Calling any definition an economic definition of income is not very meaningful and does not add much to an understanding of what is meant. Economists do not generally think of income as arising only from transactions as do most accountants. An increase in the value of an asset is income to the economist, but this 
leads to such practical difficulties that they often adopt a transaction approach in order to make the concept workable. (John T. Wheeler, page 49)

A theoretical approach to the financial accounting modeling, if practicable, would require radical alteration of accounting principles. The recognition principle would be obviated, for example, because the timing of revenue and income realization would always be assumed to be known with certainty. Maintaining records based on historical costs would become meaningless, since recorded values would be assumed to fully reflect all changes in market value of assets, including any change in value of the currency of recordation. The matching principle could be perfectly realized under assumptions of the theoretical model, because while timing of revenues and expenses affecting a period are imperfectly estimated in the applied model, they would be accurately known in the theoretical model. Moreover, certain constraints limiting an applied model would not have meaning within a theoretical model. Conservatism is followed in practice, because, faced with imperfect knowledge, practical accountants must consistently avoid all material overstatement of assets and income or understatement of liabilities as part of their responsibility to financial statement users. With perfect knowledge, no doubt would exist as to the effect economic events have on periodic income and valuation of assets. All information regarding economic events would be assumed obtainable in a no-cost or cost beneficial manner, so the theoretical model would not be constrained by cost-benefit considerations, which limit an applied model.

Theoreticians have long questioned integrity of financial accounting records, because accountants generally choose not to recognize all implicit economic events. To theoreticians, an incomplete profile of an entity's income, and hence its resources, results from failure to include both objective and implicit financial information in accounting records, so net income and asset values recorded would not always be reliable. It would follow that financial analysis resulting from these data would also be considered unreliable. Practical accountants might agree with these attitudes at a conceptual level, but have contended that difficulties of valuing many implicit events precludes their recordation, as attempts to record them might lead to manipulative distortion worse than their exclusion, as has been noted above. An applied model of the financial accounting process approximates, in a practical way, the effect economic events have on entity resources. An applied model is implemented in an economic environment where events must be imperfectly identified, imperfectly measured, and imperfectly recorded.

As with a theoretical model, the first step required in the applied model is identification of economic events. Regrettably, not all events affecting an entity will be identified by practical accountants, and those which are identified will be recorded only when sufficient objective facts support recordation and if the conservatism constraint is not violated. Even then, the value(s) finally recorded might not be accurate to the degree assumed in the primal model. This is as it must be, since appraisal values and other indicia of value are subjected to wide interpretation and manipulation. Recorded events must, however, invariably follow a dual format consistent with the economic events they describe. That is, sourcing and related using aspects of every recorded economic event are invariably recognized, and equality of sourcing and using events is carefully maintained.

Regrettably, this one difference between the theoretical and applied model continues to grate against economists, often preventing their appreciation of the work product of accountants. Although every entry in journals must identify uses and sources as equal in amount and offsetting, the value of sources and uses recorded does not have to be correctly measured in order for an applied model to work. Correctness is not a requirement for the model to be useful, even though correctness is required for a model to achieve primacy. This means that the applied model still works if bookkeepers make recordation errors, errors is estimating the value of a transaction, record events that never happened, or if accountants completely overlook certain transactions or implicit events which have occurred. The applied model works because there is only one requirement of the primal model that can never be violated, and that is the equilibrium condition. Errors, therefore, while they are not required, are clearly optional in applied accounting, and are sometimes the best option available.

Despite these and other differences, similarities between theoretical and applied models are of basic importance. Each is an economic model, which identifies and accounts for economic events. These recorded events provide a basis for all conclusions regarding an accounting entity. Additionally, conclusions reached by theoretical and applied models would be assumed to converge over the life of an accounting entity, since the same set of financial facts govern each model, and the correct financial effect of all economic events eventually would become known, 
even to practical accountants, at a time no later than the last step in a complete liquidation process.

Because of these similarities, techniques of applied accounting required by accounting principles are not unlike those which theoreticians would develop if their purpose were applied, not theoretical, economics. If cast down into the uncertain world of practicality, economic theorists would no longer have the luxury of assuming away the important realities governing applied financial accounting systems. Alternatively, techniques of theoretical accounting are not unlike those practical accountants themselves would develop if their purpose were theoretical, not applied, economics, for they would be freed from the worldly tyranny of certain economic realities which restrain them in practice. Practical accountants have difficulty thinking of themselves as practitioners of a primal equilibrium microeconomic model of an accounting entity, because they do not understand the primal requirements of the accounting process, but that would change if their overarching goal were to become theoretical.

\section{The Primal Model and Pacioli’s Bookkeeping Method}

Notice that Figure 1 represents a schematic diagram of the accounting process in terms of financial statements, and summarizes the manner in which sourcing and using activities arise. Within the figure, arrows are shown to the left and right of each statement. Arrows pointing upward should be interpreted to mean "an increase in," and those pointing downward should be read to mean "a decrease in." For example, the leftmost arrow accompanying the balance sheet should be taken to mean "an increase in assets," and the line to the right of it to mean "a decrease in assets." Note also that each arrow is subtended by the term "source" or the term "Use." These should be interpreted to mean "sources of entity resources" and "uses of entity resources," respectively.

This format illustrates the basic relationship of recordation to the underlying sourcing and using activities, which attend every economic event. For example, the balance sheet shown indicates that any activity resulting in an increase in the recorded value of an asset account(s) invariably represents a use of entity resources. Any activity resulting in a decrease in the recorded value of an asset(s) must thus be a source of resources. It can also be seen that an increase in liabilities or ownership claims occurs only in conjunction with sourcing activities, and a decrease in these claims occurs only in conjunction with using activities.

Please note that, on the income statement presented in Figure 1, all activity involving revenue or gain transactions invariably involves sourcing events, and activity involving incurring of expenses, losses or payment of dividends invariably involves uses of entity resources. Seen in this light, operations provide a periodic net source of entity resources should revenues and gains exceed expenses and losses, or a net use of resources should expenses and losses exceed revenue and gains. The only activities properly classified as uses of entity resources are activities which result in increases in assets, decreases in liabilities or ownership claims, and operating or non-operating expenses and losses.

Practical financial accountants format recorded using and sourcing events following a consistent set of bookkeeping conventions, as suggested by Pacioli. Using activities are entered on line(s) preceding any sourcing activities arising from the same economic event, and are offset slightly to the left of related sourcing events. Sourcing activities are entered on line(s) following any using activities arising from the same event, and are offset slightly to the right of related using activities. The sum of all using and all sourcing activities arising from the same economic event are recorded simultaneously, and at an identical aggregate money value, without exception. Thus, dual bookkeeping entries preserve the equality in money of all sourcing and using activities, and by entering these on different lines and columns, preserve evidence of their offsetting nature. This process of original entry will assure the equilibrium requirement is continuously met both for individual transactions and for the aggregate of all transactions at every moment in the life of an accounting entity.

As is obvious to accounting practitioners, the term "debit" is the bookkeeping equivalent of economic uses of entity resources, and the term "credit" is the bookkeeping equivalent of economic sources of entity resources. Debits invariably proxy using events and credits invariably proxy sourcing events. Through every phase of the accounting process, accountants preserve the economic integrity of their bookkeeping records, because for every recorded economic event, uses (debits) and sources (credits) of entity resources are identified as equal in amount and are shown as offsetting, as required by economic fact. 
Unfortunately, the terms debit and credit have been almost universally defined and understood by financial accountants in terms of their bookkeeping meaning, just as Pacioli encouraged, not in terms of their underlying economic meaning. For example, a leading textbook has said "The verb to debit means to make an entry in the lefthand side of an account, and the verb to credit means to make an entry on the right-hand side on an account. The words debit and credit have no other meaning in accounting." (Robert N. Anthony and James S. Reese, page 95). Other authors have made and continue to make similar assertions. While the terms "debit" and "credit" have no other bookkeeping meaning, the accounting meaning, which drives the applied model and governs all bookkeeping procedures, is itself inherently economic. This misapprehension, that Pacioli's bookkeeping terms have meaning devoid of primal economic reality, generates primal confusion among practicing accountants and accounting educators. Relatedly, accountants have also been left to wrestle with calling the basic equilibrium requirement the "accounting identity"(suggesting mathematics, not economics) or other misleading euphemisms, rather than the primal equilibrium condition, which it represents, in economic reality.

The great riddle of accountancy has been alluded to in Kohler's A Dictionary for Accountants, where both economic and bookkeeping meanings of accounting terms are acknowledged. The bookkeeping term "credit" is defined to mean "A bookkeeping entry recording the reduction or elimination of an asset or [incurrence of] an expense, or the creation of or addition to a liability or item of net worth or revenue; an entry

Figure 1: Sourcing and Using Activities in Financial Accounting Models

Balance Sheet
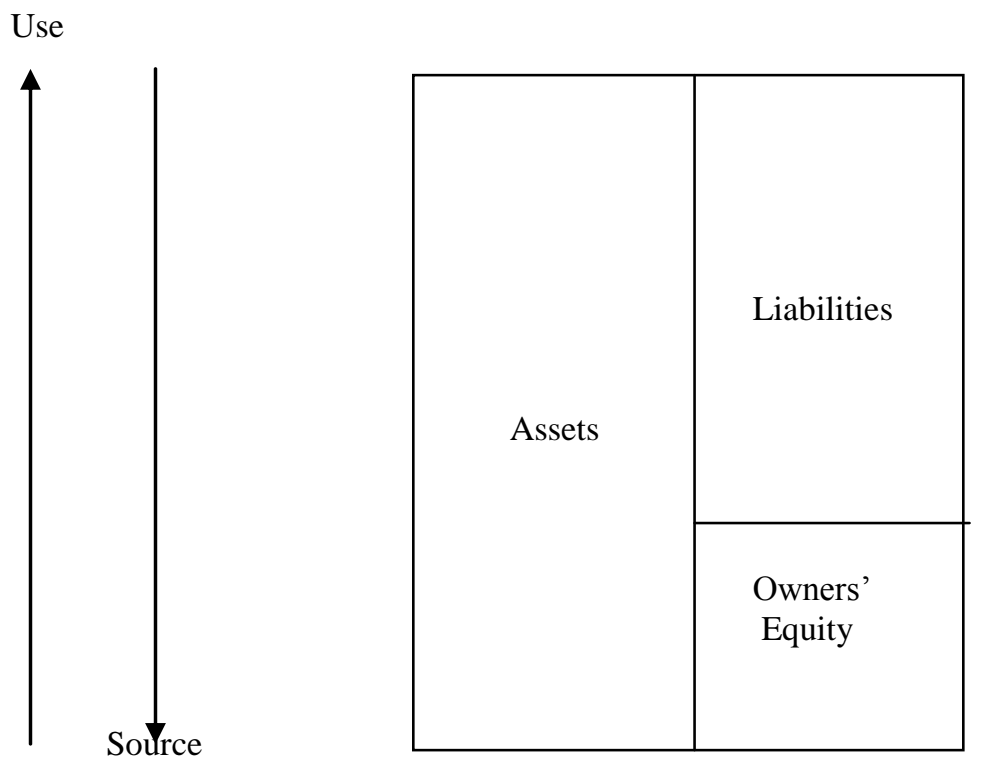

Source

\section{Income Statement}

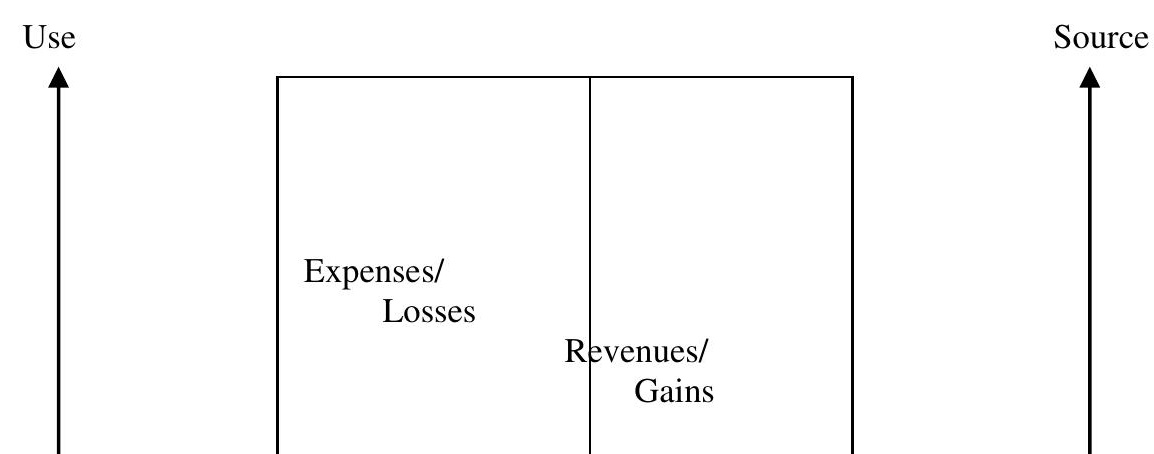


on the right side of an account [emphasis added]" (Eric L. Kohler 1975, page 147). The last phrase, the bookkeeping meaning, has unfortunately been seized upon by many accountants as the only meaning of the term "credit" in accountancy. Analogously, the definitions of economic and bookkeeping meanings are given for the term "debit" (Kohler, page 155).

Kohler's dictionary has not directly attempted any resolution of the basic misunderstanding, since it does not take the primal step of recognizing bookkeeping debits and credits as proxies for uses and sources of economic resources. Thus, accountants and students of accountancy, being aware only of the bookkeeping meanings, are left to commit to rote memory specific bookkeeping items which are properly debited and which credited, without any appreciation of the economic underpinnings of their efforts, just as their tutors have done before them. And oh, how quickly they forget! This has become even more unacceptable in a technological communications environment where the leg work of accountancy is done by computer software, because the threat exists that accountants themselves can completely lose sight of both the practical economic applications of the accounting model as well as the rules of bookkeeping that proxy economic fact.

Perhaps the most egregious assumption dividing accounting and economic disciplines is that the Kohler definitions are taken to apply to accountants only insofar as they discuss bookkeeping terms, and to economists only as they refer to sourcing and using aspects of transactions. This assumed dichotomy between practical accounting and the economic content of financial accounting models is indicative of what has become ingrained, but misguided, thinking. Both the accounting and economics communities thus seem to have forgotten that practical accounting is, at its core, applied economics!

When accounting professionals have attempted to define these terms in other than their bookkeeping meaning, their tendency has been to think of debits as "what is owned": by an accounting entity, and credits as "what is owed" as equities to agents outside the entity. While the aggregate value of assets presented on a balance sheet represent what is controlled or ephemerally "owned" by an entity, and the aggregate value of legal claims against assets represents what is "owed" to creditors and owners at a point in time, this is too limited a view of the accounting process.

Considered from a perspective of balance sheet data, there is some truth to these assertions, since an aggregate value of all assets is what is controlled at a point in time, while legal claims against those assets are aggregate equities "owed" to agents outside of the entity. However, debits representing particular economic using activities often arise from using events not increasing what is owned, and credits may arise from sourcing activities that do not increase any legal claims against assets.

The terms "sources" and "uses" of entity resources invariably describe the economic nature of recorded 
economic events correctly, so these would seem to constitute better accounting, if not bookkeeping, terms to represent the dual aspect of recorded economic events. Had Pacioli gone to this source of economic content of the financial accounting process, more than five hundred years of misdirection for accountants and economists could have been spared.

To better appreciate the distinction under discussion, consider the following: Rather than follow current bookkeeping recordation practices, accountants could, if they chose, enter credits (sources) on the first line(s) of their bookkeeping entries, and debits (uses) on succeeding line(s); also, entries could alternatively be recorded in vertical script, not horizontal script, and would not even have to be recorded on the same page(s). Countless other conventions of recordation could also be followed without loss of usefulness as long as everyone understood and subscribed to the bookkeeping rules chosen. No accepted alternative for recordation would be incorrect as long as bookkeeping entries delineated the economic value of sources and uses of economic events they describe, despite the reverence that has attended Pacioli's bookkeeping for more than five hundred years.

Also, what accountants choose to call the using and sourcing parts of bookkeeping entries is of little import (We could call them "spurts" and "starts," or "twinkies" and "oreos," for example, rather than "debits" and "credits"). Whether the term debit means "left" and the term credit means "right" when translated from Latin, as some accounting authors suggest, is immaterial in an economic sense, as direction doesn't matter. As long as sources and uses of economic resources are clearly indicated by each bookkeeping entry, and insofar as each entry clearly shows sources and uses as equal and offsetting, the particular bookkeeping format which is used is of no fundamental consequence so long as everyone subscribes to the convention. Bookkeeping conventions do not drive the primal model, as so many in the accounting profession seem to believe, but the reverse!

While it is inconceivable to imagine changing the format of bookkeeping entries at this late date in history, understanding the underlying meaning of bookkeeping terms will keep to the forefront the intimate connection between the applied accounting model and the economic events providing financial meaning to accounting records. Pacioli would certainly have wanted it so, as this, not the particular bookkeeping terms he elected to use, is the sum and substance of his lasting contribution, and all that binds him to us through these past centuries of financial accounting.

\section{Evidence of Mutual Misunderstanding}

As has been stated above, professional literature is rife with misstatements regarding the basics of accountancy. While the particular errors made manifest in the literature differ, the cause of all such errors emanates from lack of understanding of either the primal model and its meaning, or the rules of applied bookkeeping, or both. Oddly, merchants of earlier centuries might not have fallen prey to these sources of misunderstanding, because they often learned bookkeeping rules in the arena of business, and when they were trained in universities of the day, their learning was applied, not theoretical in nature.

As an indication of the problems economists have with accounting, consider the statement made by A. Pin in a presentation written for the conference celebrating the five hundredth year of Pacioli's Summa treatise: "The accounting system linked to double-entry bookkeeping is founded upon a beautiful Platonic assumption. That of unit becoming multiplicity, and of multiplicity returning to unity. Metaphorically, the concept of unit refers to net worth; that of multiplicity to assets and liabilities." (Antonio Pin, page 175)

Professor Pin seems to recognize that there exists an accounting system (a primal theoretical model); whether he does or not, he placed his thoughts in wrong order. He should have said "Double-entry bookkeeping, which links accounting records to the economic reality which it proxies . ..." The manner in which he mistakenly orders "the accounting system" and "bookkeeping" emphasizes the common misunderstanding of the differences between practical accountancy, with its rules for bookkeeping, and primal accountancy. Moreover, when he states that "the concept of unit refers to net worth," by which he means owners' equity in assets, he should have spoken of equities, or aggregate legal claims, rather than just the claims of owners. Although the truth is irrevocably lost in history, it might well be, in fact, that the stimulus for early double-entry accountancy came from creditors' desires more 
than at the behest of owners. Certainly, creditors would not elect any system which showed net assets and owners' equity only as Pin suggests, as that would obscure the assets which would stand as collateral against their legal claims. The legal claims of creditors are superior to, not inferior to, the claims of owners in actual legal and economic fact. Also, when he speaks of multiplicity, he should have spoken of assets only, because it is the multiplicity of assets, which have to be traced to the unity of legal claims against them in all systems of accountancy worldwide. It is because of such misdirections that accountants and economists have had difficulty understanding the primal model, which underlies all of accounting.

Pin also reveals elements of his misunderstanding of the applied nature of accountancy when he states that “... Whenever the wealth of one business entity is measured, the value given to each component of wealth has to be entered twice, as a debit in an asset account and as a credit in an equity account (and the value of each liability has to be entered also twice, as a credit in a liability account and as a debit in net worth account)." (Pin, page 175) Debits and credits do not, however, relate only to asset and equity accounts. They relate instead to uses and sources of entity resources, either of which might only relate to asset accounts in one instance, or only to equity accounts in another instance. Also, Pin errs when speaking of liabilities, because the value of a liability does not increase or decrease net worth. It should also be noted that there are no "net worth" accounts connected to the balance sheet as Pin speaks of them, but only asset, liability and ownership accounts. Due to his misunderstanding of the accounting process, Pin even attempts to explain the accountancy in terms of triple entry bookkeeping through use of differential calculus, math that is decidedly not germane to the primal model and not necessary to understand it.

Professor Yuji Ijiri also attempts to lend understanding to the accounting process by explaining the meaning of double entry bookkeeping. Ijiri states that "To find the essential ingredient in double-entry bookkeeping, we must focus on what ... is new and did not exist in the single-entry era. This distinguishing feature ".. is the addition of income statement accounts." (Yuji Ijiri, page 267) The point overlooked in this statement is the fact that, in their essence, all single entry and double entry accounting systems achieve the same end, which is to measure the value of the assets controlled by an accounting entity at a particular moment against an equal value of legal claims. In the case of single-entry accounting, it is assumed but not made explicit that there exist legal claims equal to the value of aggregate assets at every moment in the life of each accounting entity. In double-entry accounting, legal claims are made explicit, and that is the defining difference, not the choice to measure income. A second difficulty in Ijiri's statement relates to income statement accounts: Income statement accounts are not at all necessary either to bookkeeping or in the accounting process, although they are often thought desirable. Some accounting theorists have gone so far as to allege that an income statement is not desirable, and that income should properly be measured in the manner economists seem to prefer, as the ending aggregate value of assets less liabilities, less any de novo contributions owners might have made to an entity during the accounting period. All income statement accounts are no more than pseudonyms for increases and decreases in owners' equity, and their existence is not conceptually or practically necessary to measurement of periodic income, even though they are often deemed desirable. When it is said by accountants that the balance sheet and income statement "articulate," that, too, is a misnomer that causes misunderstanding, since income statement accounts are no more than a portrayal of events affecting owners' (and potentially creditors') equity, and can do no less than articulate.

David Solomons, a well-known British accounting theorist, has also manifested misapprehensions regarding accountancy. In his article for the March, 1995 edition on Accounting Horizons, he stated that "The purpose of this paper is to spell out the criteria that a model for preparing the traditional financial statements should meet. By "model" here is meant simply the body of accounting principles to be followed." (David Solomons, page 43) His use of the term "model" in this context manifests the problem that accountants have had since the time of Pacioli, because promulgated accounting principles at a place and time in history, while not mutually exclusive with respect to the primal model, are not the same thing. It has become so ingrained in the psyche of the accounting profession that accounting equals bookkeeping that there has been no successful attempt to relate bookkeeping conventions to the accounting model, which underlies those conventions. That is the unhappy part of the Pacioli legacy, and explains why accountants have only limited capacity to think in terms that would be acceptable to the economics profession. Solomons goes on to discuss the debate in accounting regarding the primacy question, which relates to whether the balance sheet or the income statement is of most primal importance. An understanding of the primal accounting model would quell this debate once and for all, since income measurement is a necessity. The income statement is 
no more than a part of the balance sheet, however, even though it is amenable to being presented separately. The debate should go along the lines of which specific choices constitute the most effective method of determining periodic net income, not of whether the balance sheet has primacy over the income statement, the solution to which is obvious within the primal accounting model.

Ijiri, a professor of accounting and economics, described accounting as a thing of intellectual beauty. He has said that "Double entry accounting is found to have difficulty, efficiency and originality, . . . the three ingredients of intellectual beauty . . . as stated by Goethe, Cayley and Sombart." (Ijiri, page 265) Other scientists might say that snails, bacteria and Komodo dragons are things of beauty, as they meet these criteria as well. The beauty of accounting models, practical and theoretical alike, actually lies in the unerring equilibrium requirement which is the sine qua non of accountancy. This consistency is indeed a beautiful thing, and dragons just don' have it to the degree accounting models do! Once this requirement of the primal model is understood, it is no longer difficult to understand accountancy, and there is no real originality in the discipline except in the departures from correctness in the primal model, which is required by exigencies of practical accountancy. Primal accountancy is ultimately the most efficient way to describe the economic realities associated with accounting entities, and, to that extent, Ijiri and Goethe are on target.

\section{References}

1. Anthony, Robert N. And James S. Reece. 1983. Accounting Text and Cases, seventh edition (Richard D. Irwin, Inc., Homewood, Illinois): p. 95.

2. Boulding, K. E. 1962. "Economics and Accounting: The Uncongenial Twins," in: W. T. Baxter and Sidney Davisson, eds., Studies in Accounting Theory (Richard D. Irwin, Inc., Homewood, Illinois): pp. 44-55.

3. Cronhelm, F. W. "The Principles of Equilibrium, Double Entry by Single" (London, 1818), reprinted in Richard Brief, ed., Four Classics on the Theory of Double-Entry bookkeeping (Garland Publishing, Inc., New York): pp. 1-7.

4. Edwards, Edgar O., Bell, Philip W. And Johnson, L. Todd. 1979. Accounting for Economic Events (Scholar Book Co., Houston, TX.): p. 5.

5. Ijiri, Yuji. 1995. "The Beauty of Double-Entry Bookkeeping and its Impact on the Nature of Accounting Information." in Proceedings on the Conference Accounting and Economics in Honor of the $500^{\text {th }}$ Anniversary of the Publication of Luca Pacioli's Summa de Arithmetica, Geometria, Proportioni et Proportionalita (Garland Publishing, Inc.: New York). pp. 265-285.

6. Kohler, Eric L. 1975. A Dictionary for Accountants, fifth edition (Prentice-Hall, Inc.:Englewood Cliffs, N. J.): $147 ; 155$.

7. Macve, Richard H. 1996. "Pacioli's Legacy," in Accounting History From the Renaissance to the Present (Garland Publishing, Inc.: New York). pp. 3- 30.

8. Miller, R. Emmett. 1962. No Royal Road: Luca Pacioli and His Times (The University of North Carolina Press: Chapel Hill). 445 pp.

9. Pin, Antonio. 1995. "The Contribution of Luca Pacioli to the Development of Business Accounting," in Proceedings on the Conference Accounting and Economics in Honor of the $500^{\text {th }}$ Anniversary of the Publication of Luca Pacioli's Summa de Arithmetica, Geometria, Proportioni et Proportionalita (Garland Publishing, Inc.: New York, 1995). pp. 161-177.

10. Shubik, Martin. "Accounting and its Relationship to General Equilibrium Theory," in Proceedings on the Conference Accounting and Economics in honor of the 500 ${ }^{\text {th }}$ Anniversary of the Publication of Luca Pacioli's Summa de Arithmetica, Geometria, Proportioni et Proportionalita (Garland Publishing, Inc.: New York). pp. 226-234.

11. Solomons, David. 1995. "Criteria for Choosing an Accounting Model." Accounting Horizons. 2(1) pp.4251.

12. Wheeler, John T. 1995. "Economics and Accounting," in Handbook of Modern Accounting Theory, ed. by Backer, Morton. 1955 (Prentice-Hall, Inc., New York): p. 49. 